\title{
On Decipherment of the Inscriptions of Linear A in the Common Kartvelian Language
}

\author{
Gia Kvashilava \\ Researcher, Institute of Theoretical and Applied Linguistics, Ivane Javakhishvili Tbilisi State \\ University and Sokhumi State University, Tbilisi, Georgia
}

13, Chavchavadze Ave., TSU, 8th Building, Office 308, 0179 Tbilisi, Georgia

(+995) 555362051

\begin{abstract}
The object of this paper is deciphering of Cretan Linear A inscriptions spread mainly across the Aegean area.

1. The paper presents a brief background of the ancient population of the Peloponnese, Asia Minor and the Aegean islands before the Indo-European migrations.

It is supposed that the indigenous inhabitants of this area were of non-Indo-European and non-Semitic origin.

2. The study of the linguistic material and graphical qualities of Linear $A$, and the phonetic reading of Linear $B$ script by $M$. Ventris, granted the correctness of my decipherment of Linear A inscriptions in the Common Kartvelian.

Some of the deciphered Linear A words are the following:

a. Words for numeral operations: (addition) ku-ro - "to bind, gather, collect, add", and (subtraction) ki-ro - "fault, defect; to subtract, lessen, diminish, cut off"; $b$. Names of vessels for liquid - qa-pas, ka-ti, and ka-di;

c. The toponyms and anthroponyms: pa-i-to - "Phaistos"; a-ja - "Aea"; ku-ta- - "Cyta[ea]"; kuku-da-ra - "a Colchian person"; ma-ka-ri-te - "the is/and of Macris/Euboea (Macrean or Macrones tribe)".
\end{abstract}

Keywords: Linear A script, the Common Kartvelian language, comparative and inner reconstructions. 
